\title{
Role of squamous cell carcinoma antigen-1 on liver cells after partial hepatectomy in transgenic mice
}

\author{
GIANMARCO VILLANO $^{1}$, SANTINA QUARTA ${ }^{1}$, MARIA GRAZIA RUVOLETTO ${ }^{1}$, CRISTIAN TURATO $^{1}$, \\ LAURA VIDALINO $^{1}$, ALESSANDRA BIASIOLO ${ }^{1}$, NATASCIA TONO $^{2}$, FRANCESCA LUNARDI ${ }^{3}$, \\ FIORELLA CALABRESE ${ }^{3}$, LUIGI DALL'OLMO ${ }^{4}$, ARBEN DEDJA ${ }^{4,5}$, GIORGIO FASSINA ${ }^{6}$, \\ ANGELO GATTA $^{1}$ and PATRIZIA PONTISSO ${ }^{1}$
}

\begin{abstract}
${ }^{1}$ Department of Clinical and Experimental Medicine, University of Padova; ${ }^{2}$ Istituto Oncologico Veneto - I.R.C.C.S, Padova; Departments of ${ }^{3}$ Diagnostic Medical Sciences and Special Therapies; ${ }^{4}$ Surgical and Gastroenterological Sciences, University of Padova; ${ }^{5}$ Consorzio per la Ricerca sul Trapianto d'Organi;

${ }^{6}$ Xeptagen S.p.A.,VEGA Science Park, Venezia, Italy
\end{abstract}

Received June 12, 2009; Accepted August 14, 2009

DOI: 10.3892/ijmm_00000323

\begin{abstract}
Squamous Cell Carcinoma Antigen-1 (SCCA1) overexpression has been observed in tumours of epithelial origin and in hepatocellular carcinoma. Previous data indicate that this serpin inhibits apoptosis, while its proliferative activity was only recently proposed. The aim of this study was to evaluate the effect of SCCA1 on liver cells in a transgenic mouse model after partial hepatectomy. Twenty-one C57BL/6J mice (11 transgenic for human SCCA1, 10 wild-type) underwent partial hepatectomy and were sacrified after one week. Apoptosis and proliferation markers were determined in the liver at sacrifice, while a cytokine panel was measured in serum. Transgenic mice showed a relative liver weight significantly higher than wild-type mice at sacrifice (mean $\pm \mathrm{SD}, 5.38 \pm 0.50 \%$ vs $4.84 \pm 0.29 \%, \mathrm{p}=0.0221$ ), while no difference $(p=0.2403)$ was observed in two untreated control groups ( 6 transgenic, 6 wild-type mice). Active caspase- 3 was significantly lower in transgenic mice than in wild-type mice $(\mathrm{p}=0.0047)$. The transgenic mouse group showed overall higher proliferative activity at sacrifice, compared to wild-type mice, with increased proliferation parameters. Cytokine analysis revealed a remarkable and opposite sex-dependent behaviour of interleukin (IL)-6 after hepatectomy. At variance with wild-type mice, a significant IL-6 increase was documented only in transgenic females $(\mathrm{p}=0.0313)$, even more relevant than that observed in wild-type males. In conclusion, transgenic mice expressing SCCA1 showed higher liver regenerative
\end{abstract}

Correspondence to: Professor Patrizia Pontisso, Clinica Medica 5, Department of Clinical and Experimental Medicine, Via Giustiniani 2, I-35123 Padova, Italy

E-mail: patrizia@unipd.it

Key words: apoptosis, cell proliferation, C57BL/6J mouse, ov-serpin, squamous cell carcinoma antigen-1, transgenic mouse potential compared to wild-type mice, supporting the dual role of this serpin as an anti-apoptotic and pro-proliferative stimulus for liver cells in vivo.

\section{Introduction}

The serpins are a family of serine protease inhibitors involved in multiple biological functions and cell homeostasis control (1). They are characterized by unique common structural features and inhibitory mechanisms (2). Human serpins are phylogenically divided into nine clades and squamous cell carcinoma antigen 1 (SCCA1 or SERPINB3) is one of the 13 members of the ov-serpin family included in clade $\mathrm{B}$, where members share a similar amino acid sequence (39-50\%), common structural features, lack of the signal sequence found in other serpins and similar gene organization (3).

Two isoforms (SCCA1 or SERPINB3 and SCCA2 or SERPINB4) were originally purified from squamous cell carcinoma of the uterine cervix (4). Genomic cloning and sequencing revealed that they are $91 \%$ identical at the amino acid level, but show distinct properties and substrates (5) and their physiological roles are poorly understood.

While they are expressed in normal epithelia, overexpression in neoplastic cells of epithelial origin $(6,7)$ and hepatocarcinoma $(8,9)$ have been observed. Both SCCA1 and SCCA2 protect neoplastic cells from apoptotic death induced by several kinds of stimuli, and their suggested molecular target is located upstream of caspase-3 (10).

More recent data indicate that upon exposure of keratinocytes to ultraviolet light, SCCA1 translocates to the nucleus and its binding to phosphorylated JNK1 inhibits UV-induced apoptosis (11). In vivo experiments have demonstrated that SCCA1 promotes tumor growth inhibiting intratumor infiltration of natural killer cells (12). In addition, recent findings from our group suggest that this serpin induces cell proliferation and epithelial mesenchymal transition (13).

Liver regeneration after partial hepatectomy serves as a model for studying normal growth factor signals that become aberrant in cancer. This process is a peculiar aspect of all 
vertebrates which consists mainly of compensatory hepatic growth with the goal of replacing functional mass after parenchymal cell loss induced by traumatic, viral, pharmacological or surgical causes (14).

After surgical removal of the mass of a healthy liver, the remaining tissue undergoes rapid regeneration of its lost mass, usually within a week after surgery $(15,16)$. The fine control of liver weight recovery during regeneration is a complex process that involves both mitosis and apoptosis that are strictly and chronologically regulated. This program involves changes in gene expression and in multiple signalling pathways of different hepatic cell types. New interactions, based on the production of growth factors, cytokines and neuroendocrine factors, occur simultaneously in the initial steps (17). Between 60 and 96 h later a wave of apoptosis occurs through the liver. The number of apoptotic cells is directly proportional to the magnitude of the proliferation phase (18). Despite the large number of signalling networks already discovered, the number of known molecules involved in liver regeneration is continuously growing and among cytokines, interleukin-6 (IL-6) is considered a key player, acting not only as mitogenic, but also as an anti-apoptotic factor for hepatocytes (19).

In the present study the effect of SCCA1 on liver cells was assessed using an in vivo model of mice transgenic for SCCA1 undergoing partial hepatectomy.

\section{Materials and methods}

Characterization of transgenic mice. The study was carried out in C57BL/6 mice transgenic for human SCCA1 (kindly provided by Professor G. Cassani, Technogen S.c.p.A, Piana di Monte Verna, CE, Italy). The sequence of human SCCA1 $(-7 /+1238)(5)$ was inserted into the pcDNA3 plasmid vector under the $\alpha 1$-antitripsin $(\alpha 1 \mathrm{AT})$ promoter.

Mice were bred at the Animal Care Facility of the Experimental Surgery Division of the University of Padua. To better characterize the transgenic mouse model, the expression of SCCA1 was assessed in preliminary experiments in different organs (liver, brain, lung, genitals, kidney and muscle).

Liver regeneration model. To induce liver regeneration, onethird hepatectomy was carried out in 11 transgenic mice ( 6 females and 5 males) and in 10 wild-type mice ( 5 females and 5 males) (Charles River Italia S.p.A, Calco, Lecco), aged 10-12 weeks, following the recommendations of Greene and Puder (20) to ensure minimal morbidity.

After surgery, mice were given $1 \mathrm{ml}$ sterile saline solution subcutaneously, daily monitored and sacrified on day 7 by injection of a lethal dose of tiletamine hydrochloride. For liver regeneration parameters, the weight of the explanted liver was used to define the relative liver weight (ratio between liver weight/body weight at sacrifice) (21). This parameter was also assessed in 12 untreated control mice ( 6 transgenic and 6 wild-type) to define liver baseline characteristics of the transgenic model. Both surgically removed and explanted livers were cut in two parts, one part was fixed with $4 \%$ paraformaldehyde in PBS, followed by paraffin embedding, while the other part was immediately frozen in liquid nitrogen and stored at $-80^{\circ} \mathrm{C}$ for further analysis. Serum samples were obtained by tail venipuncture in all mice at the beginning of the study and at the time of sacrifice.

The experimental protocol was approved by the Animal Investigation Committee of the Italian Ministry of Health and all measures were taken to minimize any pain or discomfort of the animals.

\section{Immunohistochemistry}

SCCA1 expression. All liver specimens were immunostained with a polyclonal rabbit anti-SCCA antibody (Hepa-Ab, Xeptagen, Italy) as previously described (8). Samples were processed using a sensitive avidin-streptavidin-peroxidase technique and stained with a mixture of 3,3-diaminobenzidine tetrahydrochloride and hydrogen peroxide. Parallel control slides were prepared either lacking primary antibody or primary and secondary antibodies, or were stained with normal sera to control for background reactivity.

The percentage of stained cells in each specimen was scored from 0 to 3 , score 0 denoting negative staining, score 1 positive in $1-30 \%$ of hepatocytes, score 2 in $31-50 \%$ and score 3 in $>50 \%$.

Proliferative activity quantification. Proliferative activity was assessed by counting mitotic nuclei on hematoxylin eosin (H\&E) and by immunohistochemistry for BrdU and Ki67. Mitoses were counted on H\&E sections at x400 using an Olympus B X 40 microscope. The mitotic index was expressed as the number of mitotic figures per $10 \mathrm{high} /$ power fields (HPF).

After deparaffinization and hydration, liver sections $(4 \mu \mathrm{m})$ were incubated at room temperature with anti-BrdU monoclonal antibody (Amersham, UK) for $1 \mathrm{~h}$. The avidin-biotin technique was then performed with matched components (secondary-biotinylated antibody and avidin-peroxidase complex) of the Vectastain ABC kit (Vector Laboratories, Burlingame, CA) according to the manufacturer's instructions. Diaminobenzidine, together with cobalt and nickel ions used to intensify and increase the contrast of the resulting stain, was used as chromogen to localize BrdU immunoreactivity. Cells were considered labelled when nucleus showed dense reaction products.

For morphometric analysis, the liver nuclei labelled with BrdU were counted at high power field. Anti-Ki67 (MIB-1, Immunotech, Marseille, France) monoclonal antibody was used at 1:50 dilution. Ki67 immunostaining was randomly evaluated counting at least 1,000 nuclei. The percentage of positive nuclei was expressed as Ki67 labelling index.

\section{Molecular techniques}

Polymerase chain reaction (PCR) for human SCCA1. To screen for transgenic mice, genomic DNA was isolated from mouse tails and the following vector-specific primers were used for amplification ( $\alpha 1 \mathrm{AT}$ upstream, 5'-GCCACTAAGG ATTCTGCAGTGAGAGG-3'; downstream, 5'-ACATCCAA CCAGCTGTTAAGATGCG-3'; BGHpolyA+ upstream, 5'-GCA GAAGCTGCAGCTGCCACC-3'; downstream, 5'-TGACAC CTACTCAGACAATGCGATGC-3').

PCR parameters for the Thermal Cycler 480 (Perkin Elmer, Norwalk, CT) were $95^{\circ} \mathrm{C}$ for $5 \mathrm{~min}$, followed by $62^{\circ} \mathrm{C}$ for $1 \mathrm{~min}$ and $72^{\circ} \mathrm{C}$ for $1 \mathrm{~min}\left(1\right.$ cycle); $95^{\circ} \mathrm{C}$ for $1 \mathrm{~min}$, followed by $62^{\circ} \mathrm{C}$ for $1 \mathrm{~min}$ and $72^{\circ} \mathrm{C}$ for $1 \mathrm{~min}$ (40 cycles) and the last cycle of $95^{\circ} \mathrm{C}$ for $1 \mathrm{~min}$, followed by $62^{\circ} \mathrm{C}$ for 
$1 \mathrm{~min}$ and $72^{\circ} \mathrm{C}$ for $5 \mathrm{~min}$. The amplified products generated a 645-bp band for $\alpha 1 \mathrm{AT}$ and a 380-bp band for BGHpolyA+, visualized by ethidium bromide after agarose gel electrophoresis.

Quantitative real-time PCR (SYBR green assay). The extent of human SCCA1 expression in the liver was assessed by real-time PCR. Total RNA was extracted from frozen tissue using Trizol Reagent (Invitrogen, Carlsbad, CA) according to the manufacturer's instructions.

Extracted RNA $(2 \mu \mathrm{g})$ for each tissue sample were reverse transcribed into cDNA first-strand by First Strand cDNA Synthesis kit, using 200 U of SuperScript II Reverse Transcriptase and $0.5 \mu \mathrm{g}$ of oligo dT (Invitrogen). The SYBR Green real-time PCR was performed with a Light Cycler Apparatus (Roche, Monza, Italy), using a FastStart DNA Master ${ }^{\text {PLUS }}$ SYBR Green Kit ${ }^{\mathrm{TM}}$ (Roche, Monza, Italy) in glass capillaries.

Primers were designed from the published sequence of human SCCA1 mRNA (accession number GenBank ${ }^{\mathrm{TM}}$ NM_006919) and the nucleotide sequence was as follows, sense, 5'-GCAAATGCTCCAGAAGAAAG-3'; antisense, 5'-CGAGGCAAAATGAAAAGATG-3'.

After an initial denaturation step at $95^{\circ} \mathrm{C}$ for $10 \mathrm{~min}$, 45 cycles of amplification were carried out and included the following conditions, denaturation at $94^{\circ} \mathrm{C}$ for $1 \mathrm{sec}$, annealing at $58^{\circ} \mathrm{C}$ for $10 \mathrm{sec}$ and extension at $72^{\circ} \mathrm{C}$ for $10 \mathrm{sec}$. Amplification of specific transcripts was confirmed by melting curve profiles at the end of each PCR cycle, using the specific routine built-up in the Light Cycler instrument. A final extension step was performed at $37^{\circ} \mathrm{C}$ for $1 \mathrm{~min}$.

The amplified product generates a fragment of $261 \mathrm{bp}$. Size and homogeneity of amplified PCR fragments were checked after electrophoresis in $1.5 \%$ agarose gel and ethidium bromide staining.

Human SCCA1 mRNA quantification, through the standard curve, was established using serial 10-fold dilutions of the target human SCCA1 gene derived from a pUC18 plasmid vector containing the cDNA sequence of human SCCA1 (22).

The SCCA1 cDNA was recovered and purified by low melting point agarose gel electrophoresis after digestion by $\mathrm{SaCI}$ and BamHI endonucleases (New England Biolabs, Beverly, MA). Absolute quantification in each sample was expressed as pg per $\mu$ g RNA (23).

To determine the behaviour of the mouse-homologous serpin during hepatic regeneration, the expression of mouse specific mRNA was assessed in transgenic and in wild-type mice. The following set of primers, sense, 5'TTTGGCTGAA CAAGAACACA3'; antisense, 5'AAGTCAGCCTTCTGTGG ATCA3') was used, that allowed the amplification of the mouse SERPINB3a, -B3b, -B3c, and -B3d, which are homologous to human SCCA1 $(24,25)$.

Western blot analysis. The expression of human SCCA1, cleaved caspases-3 and B-actin was assessed by Western blot analysis using cellular extracts of liver tissue. Liver homogenates were extracted by $1 \mathrm{ml}$ of solution ( $\mathrm{pH}$ 7.4) containing $210 \mathrm{mM}$ mannitol, $70 \mathrm{mM}$ sucrose, $10 \mathrm{mM}$ Hepes and $1 \mathrm{mM}$ EGTA, then $1 \mathrm{ml}$ of a second solution $(150 \mathrm{mM} \mathrm{NaCl}, 10 \mathrm{mM}$ Tris, 1 mM EDTA, 1 mM EGTA, $2 \%$ Triton X-100, pH 7.4) and $150 \mu \mathrm{l}$ protease inhibitor cocktail $1 \mathrm{X}$ (Roche, Mannheim, Germany) were added.
The lysates were centrifuged at 100,000 x g for $30 \mathrm{~min}$ at $4^{\circ} \mathrm{C}$ in a Beckman Coulter MLS-50 ultracentrifuge. Total protein from each liver specimen $(100 \mu \mathrm{g})$, quantified by BCA Protein Assay Kit (Pierce Biotechnology, Rockford, IL, USA), was separated by $10 \%$ polyacrylamide gel and transferred to nitrocellulose membrane.

All antibodies were diluted with phosphate-buffered saline (PBS) solution containing 2\% non-fat dry milk. Antigenic detection was carried out by enhanced chemiluminescence (Amersham, Arlington Height, IL, USA) and densitometric analysis was assessed using VersaDoc Imaging system (BioRad Laboratories, Hercules, CA, USA). After stripping, each blot was assayed for $B$-actin content as standardization of sample loading.

The quantitative densitometric value of each protein was normalized to $B$-actin and displayed in histograms. The expression of each protein was detected using the following antibodies: polyclonal anti-human SCCA (Hepa-Ab, 1:462, Xeptagen, Venice, Italy), polyclonal anti-cleaved caspase-3 (1:1,000, Cell Signaling Technology, Danvers, MA, USA), monoclonal anti- $\beta$-actin $(1: 1,000$, Sigma-Aldrich, St. Louis, MO, USA), anti-mouse IgG (1:1,000, Amersham Bioscience) and anti-rabbit $\mathrm{IgG}$ horseradish peroxidase conjugated secondary antibodies (1:2,000, Sigma-Aldrich).

Serologic assays. Liver function was monitored by analyzing albumin concentration which was measured in serum by a colorimetric assay (Eurokit S.r.l., Gorizia, Italy) according to the manufacturer's instructions. Albumin concentration in each sample was expressed in $\mathrm{g} / \mathrm{dl}$ and calculated using a calibration curve obtained by serial dilutions of the reference standard, ranging from 4 to $0.5 \mathrm{~g} / \mathrm{dl}$.

Cytokine assays. A panel of eight mouse cytokines (IL-1ß, IL-2, IL-4, IL-5, IL-10, GM-CSF, IFN- $\gamma$ and TNF- $\alpha$ ) was analyzed in plasma samples of both transgenic and wild-type mice obtained at sacrifice, using the Bio-Plex protein assay (Bio-Rad, Hercules, CA, USA).

This platform for bead-based assays combines the concept of flow cytometry with dual red and green lasers for simultaneous bead and reporter detection and allows simultaneous identification of beads complexed with different biomolecules. The results were analysed by X-Map technology (Luminex, Mirai Bio, Alameda, CA, USA) using a Bio-Plex system (Bio-Rad Laboratories) following the manufacturer's instructions.

Serum concentrations of IL-6, one of the main cytokines involved in liver regeneration and not included in the available panel described above, were determined at baseline and at sacrifice using a mouse IL-6 enzyme-linked immunosorbent assay (ELISA) quantification kit (BioSource, Nivelles, Belgium), according to the manufacturer's specifications.

The microplate wells were read at $450 \mathrm{~nm}$ using an Ortho Diagnostic System plate reader and IL-6 concentration was assessed on the basis of a calibration curve, using standards provided in the kit.

Statistical analysis. Statistical analysis was carried out using the Student's t-test, the non-parametric Mann-Whitney test and Wilcoxon matched pairs test, when appropriate. All tests 

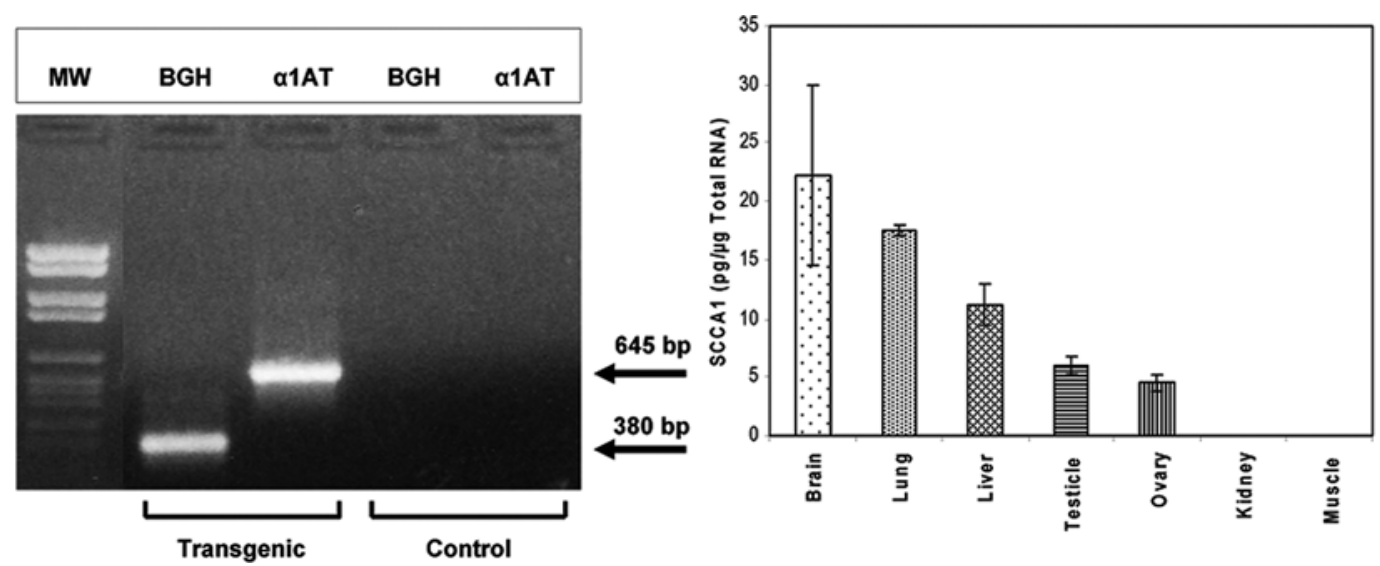

Figure 1. Molecular characterization of the SCCA1 transgenic mice model. Left panel, example of PCR amplification using vector-specific primers for $\alpha 1$ antitripsin ( $\alpha 1 \mathrm{AT}$ ) and for BGHpolyA+ (BGH). DNA was extracted from the tail of a SCCA1 transgenic mouse (transgenic) and of a wild-type C57BL/6 mouse (control). Arrows indicate the expected molecular weight of $645 \mathrm{bp}$ for a1AT and of $380 \mathrm{bp}$ for BGH. MW, molecular weight marker. Right panel, distribution of SCCA1 mRNA in different tissues of transgenic mice assessed by real-time PCR. Columns represent mean levels and bars denote standard error (SE).

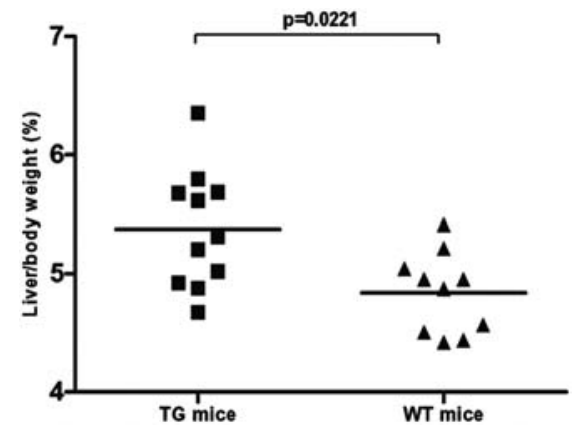

Figure 2. Distribution of the relative liver weight in transgenic (TG) and in wild-type (WT) mice 7 days after partial hepatectomy. Horizontal bars represent mean values in the two groups.

were two-tailed. The significance was set as $\mathrm{p}<0.05$. All analyses were performed using GraphPad InStat software (San Diego, CA, USA).

\section{Results}

Characterization of transgenic mice. DNA amplification of transgenic mice with vector-specific primers generated a single band migrating at the expected size of $645 \mathrm{bp}$ for $\alpha 1 \mathrm{AT}$ and of $380 \mathrm{bp}$ for BGHpolyA+ (Fig. 1).

As shown in Fig. 1, human SCCA1 mRNA expression in transgenic mice was detected at different levels in the examined organs. The amount of transcripts was higher in the brain (mean \pm SD, 22.25 $\pm 10.96 \mathrm{pg} / \mu \mathrm{g}$ RNA), lung (mean $\pm \mathrm{SD}$, $17.5 \pm 0.71 \mathrm{pg} / \mu \mathrm{g}$ RNA) and liver (mean $\pm \mathrm{SD}, 11.25 \pm 2.47 \mathrm{pg} / \mu \mathrm{g}$ RNA), while it was low in the genitals (mean $\pm \mathrm{SD}, 6 \pm 1.06 \mathrm{pg} / \mu \mathrm{g}$ RNA for testicle and $4.5 \pm 1.06 \mathrm{pg} / \mu \mathrm{g}$ RNA for ovary), and trivial in kidney and muscle (mean $\pm \mathrm{SD},<0.6 \mathrm{pg} / \mu \mathrm{g}$ RNA).

No amplification for human SCCA1 was detectable in wild-type mice. The mouse-homologous SCCA1 mRNA was not detectable in wild-type nor transgenic mice at baseline and after hepatectomy.

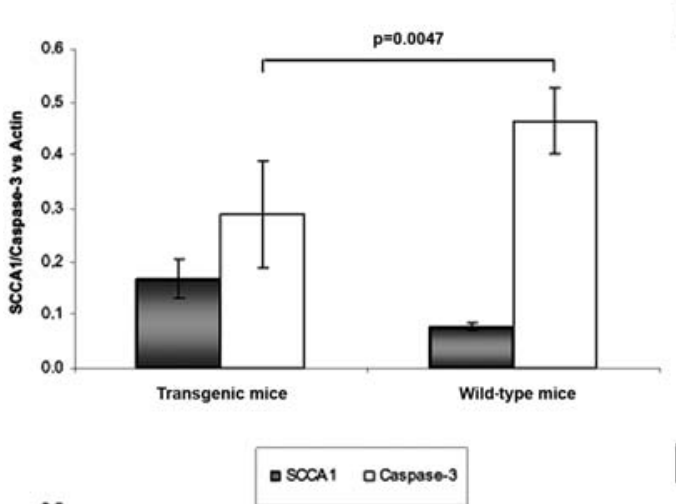

A

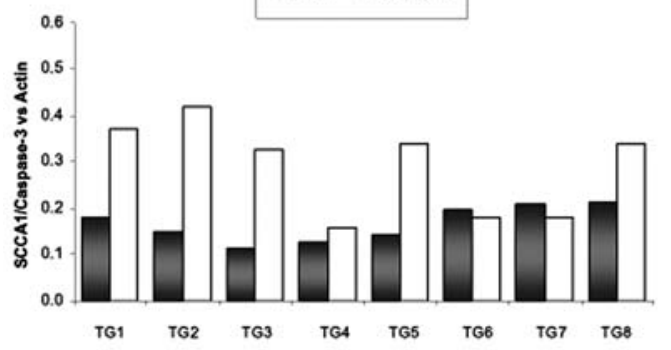

Figure 3. Apoptotic activity compared to SCCA1 expression in the liver was detected by Western blot analysis at sacrifice. (A) Mean levels of cleaved/activated caspase-3 (white columns) and of SCCA1 (grey columns) in transgenic and in wild-type mice. A significantly lower amount of caspase-3 is detectable in transgenic mice, compared to wild-type mice. SCCA1 expression is detectable in transgenic mice, while trivial values are shown in the control group. The quantitative densitometric values are normalized to B-actin. Bars represent standard error (SE). (B) Example of SCCA1 and caspase-3 expression in the liver of individual transgenic mice (TG1-TG8). The quantitative densitometric values are normalized to $ß$-actin.

Liver regeneration in transgenic mice. The regenerative activity of the liver was expressed as relative liver weight. As shown in Fig. 2, the relative liver weight was significantly higher in transgenic mice than in wild-type mice (mean $\pm \mathrm{SD}$, $5.38 \pm 0.50 \%$ vs $4.84 \pm 0.29 \%, p=0.0221$ ), while in the control groups of untreated mice no significant difference of relative liver weight was detected (mean $\pm \mathrm{SD}$, transgenic, $5.41 \pm 0.17 \%$ vs wild-type, $5.03 \pm 0.21 \%$, $\mathrm{p}=0.2403$ ). 


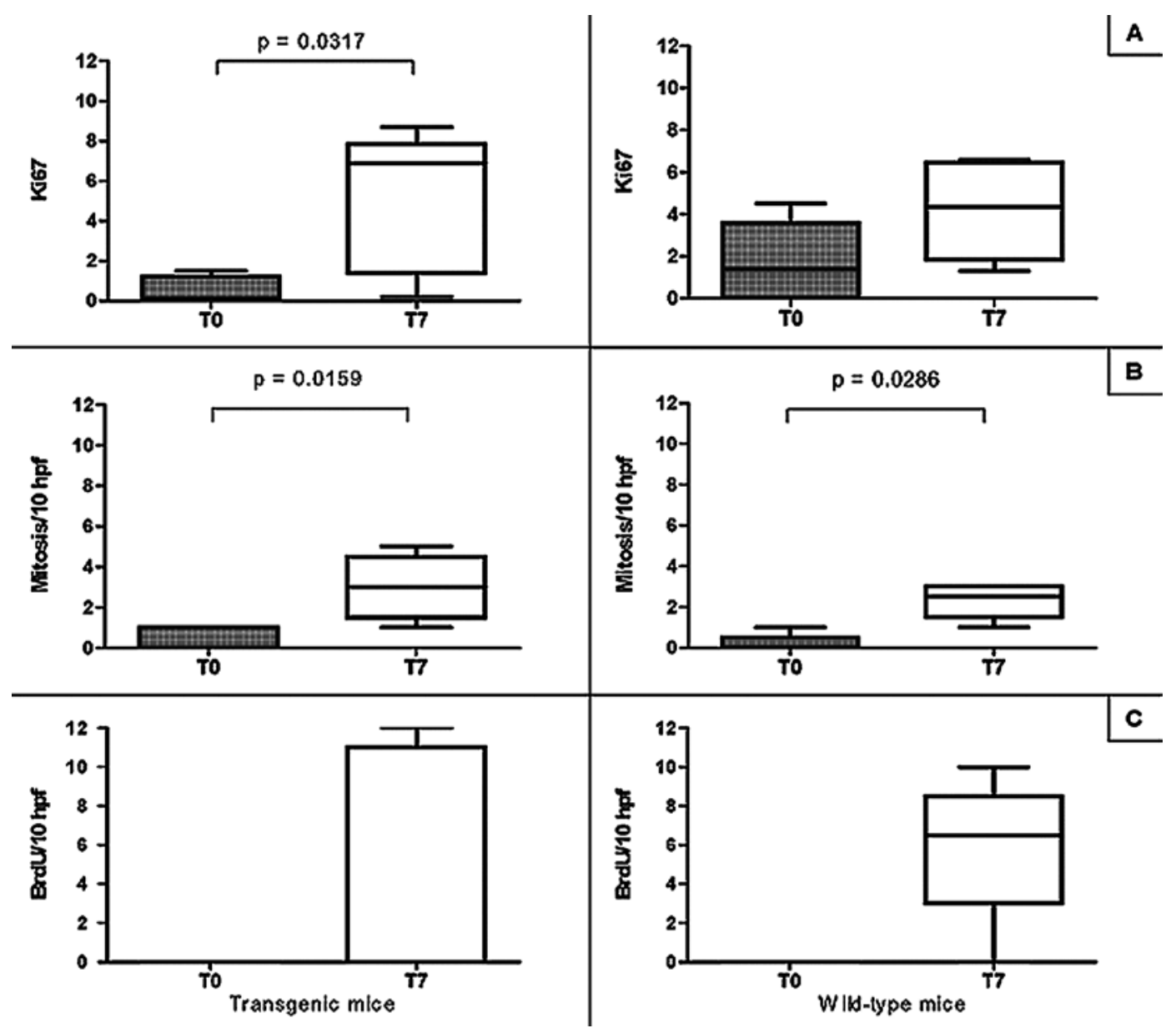

Figure 4. Proliferation parameters in transgenic and wild-type mice in surgically removed liver (T0) and in remnant liver at sacrifice, carried out at day 7 after surgery (T7). Box plot of Ki67 index (A), mitosis number (B) and BrdU staining (C) are represented. The box indicates the lower and the upper quartile and the middle line indicates the median. Bars indicate the range of value distribution.

The growth advantage observed in the transgenic mouse group was associated to decreased apoptotic activity, as documented by lower levels at sacrifice of cleaved/activated caspase- 3 expression in transgenic mice, compared to the wild-type mouse group ( $\mathrm{p}=0.0047$ ) (Fig. 3).

In addition, the transgenic mouse group showed overall higher proliferative activity at sacrifice, compared to T0, than wild-type mice. Beside the significant increase of the mitosis number observed in both groups, in transgenic mice a significant increase of Ki67 expression ( $\mathrm{p}=0.0317$ ) was also documented (Fig. 4).

Cytokine profiles. Fig. 5 reports the results of circulating cytokine concentrations in transgenic and wild-type mice at sacrifice. The wide range of variation detected in individual animals did not allow identification of significantly different profiles of the explored cytokines. The measurement of IL-6 concentrations after hepatectomy showed a significant increase, compared to baseline, both in transgenic (mean $\pm \mathrm{SD}$, $103.9 \pm 192.2 \mathrm{pg} / \mathrm{ml}$ vs $12.3 \pm 0.12 \mathrm{pg} / \mathrm{ml}, \mathrm{p}=0.001$ ) and in wildtype mice (mean $\pm \mathrm{SD}, 69.2 \pm 164.9 \mathrm{pg} / \mathrm{ml}$ vs $13 \pm 1.35 \mathrm{pg} / \mathrm{ml}$, $\mathrm{p}=0.002$ ). However, a marked sex-dependent behaviour was found, as shown in Fig. 6. The transgenic female group showed a significant IL-6 increase after hepatectomy (mean $\pm \mathrm{SD}$, 171.9 $\pm 248.2 \mathrm{pg} / \mathrm{ml}$ vs baseline, $12.27 \pm 0.1 \mathrm{pg} / \mathrm{ml}, \mathrm{p}=0.0313)$,

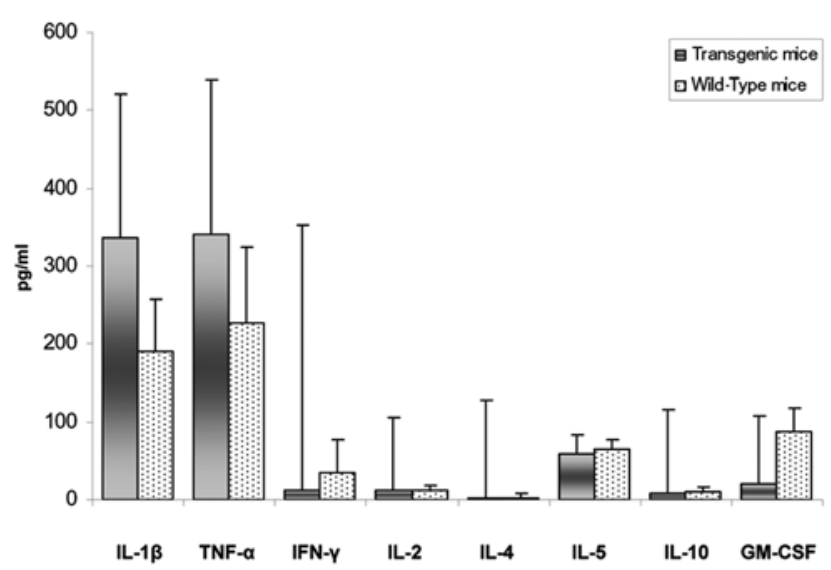

Figure 5. Profile of serum cytokines at sacrifice in transgenic and in wildtype mice detected by the Bio-Plex protein assay. Columns represent mean levels and bars denote the standard error (SE).

not detectable in the transgenic male group nor in wild-type females. As expected, the IL-6 increase in wild-type mice after hepatectomy was markedly higher in males than in females, although not reaching statistical significance.

Concerning albumin synthesis, a slight decrease of serum albumin concentration at sacrifice was detected in both groups, 

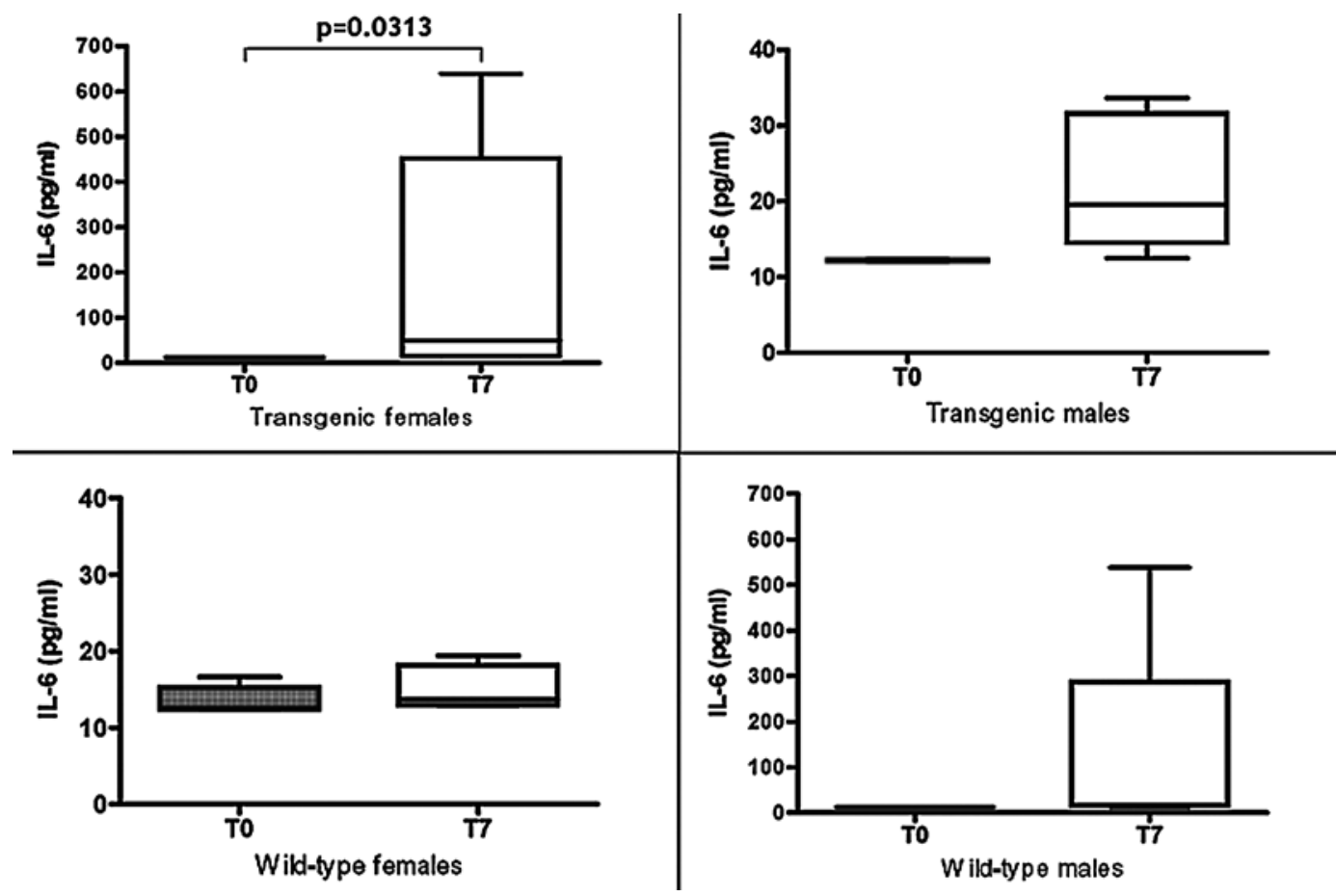

Figure 6. Behaviour of IL-6 in relation to sex difference after partial hepatectomy. In transgenic mice and in controls serum IL-6 was determined at the time of surgery (T0) and at the sacrifice (T7). The box indicates the lower and the upper quartile and the middle line indicates the median value of IL-6. Bars indicate the range of value distribution.

reaching statistical significance in the transgenic mice group (mean $\pm \mathrm{SD}$, wild-type mice baseline, $3.4 \pm 0.42 \mathrm{~g} / \mathrm{dl} \mathrm{vs}$ sacrifice, $2.78 \pm 0.46 \mathrm{~g} / \mathrm{dl}, \mathrm{p}=0.275$; transgenic mice baseline, $3.29 \pm 0.13 \mathrm{~g} / \mathrm{dl}$ vs sacrifice, $2.82 \pm 0.30 \mathrm{~g} / \mathrm{dl}, \mathrm{p}=0.001)$.

\section{Discussion}

Liver regenerative response involves a number of growth factors, cytokines and transcriptional factors as important regulators of this process $(14,17)$. Partial hepatectomy followed by liver regeneration represents a suitable model to assess the effect of new molecules on liver cell homeostasis. In the present study we provide evidence of a dual effect of the serpin SCCA1, consisting in anti-apoptotic and pro-proliferative activities, leading to a final improvement of liver growth after partial hepatectomy.

Both SCCA1 and SCCA2, not detectable in normal liver, were observed overexpressed in epithelial tumours $(6,7)$, in primary liver cancer $(8,9$,$) and in preneoplastic liver lesions$ (26) while a lower level of expression was found in chronically damaged livers, especially in liver cirrhosis (27). The biological role of these isoforms is not completely known and Suminami et al have shown that they regulate tumor growth not only by protecting cells from apoptosis through the decrease of caspase-3 activation (10), but also by inhibiting innate immune response (12). Recent findings obtained in our laboratory indicate that SCCA1 induces an increase of cell proliferation and downregulation of the adhesion system, with typical features of epithelial mesenchymal transformation (13).

To better address these aspects, in our study we have used transgenic mice to explore the effect of SCCA1 on regenerating liver cells after partial hepatectomy. Our findings indicate that the presence of SCCA1 in transgenic mice acted as a strong stimulus for liver growth through the decrease of cell apoptosis and increase of cell proliferation. Since the peak of proliferative activity occurs $\sim 48 \mathrm{~h}$ after hepatectomy, followed by the remodelling wave of apoptosis (18), the timing of sacrifice in our experimental model, chosen to assess the regenerative event in toto, has allowed to better document the difference in apoptotic activity, rather than in the proliferation that was likely in the decreasing phase at the time of analysis.

Among the explored cytokines, IL- 6 showed a peculiar behaviour in liver regeneration of transgenic animals compared to wild-type mice (28). A striking and opposite sex-dependent behaviour was indeed observed in the two groups of mice. Wild-type males showed increased IL-6 values, compared to females, as previously reported (29), while a similar behaviour was detected only in transgenic females, but not in males of the corresponding group. This unexpected finding suggests that, while estrogens play a crucial role in MyD88-dependent suppression of IL-6 production in wild-type mice (29), SCCA1 modulates the production this cytokine after hepatectomy, contrasting estrogen activity. Further studies are needed to better understand the precise mechanism of action of this serpin, determining its relationship with sex-related hormones and the involved pathways.

In conclusion, our results support the hypothesis that SCCA1 exerts a dual role, conferring resistance to apoptotic cell death and acting as an additional stimulus for liver cell proliferation, with opposite sex-dependent behaviour on IL-6 production.

\section{Acknowledgements}

This work was supported in part by a grant from the Città della Speranza Foundation, Italy. 


\section{References}

1. Silverman GA, Bird PI, Carrell RW, et al: The serpins are an expanding superfamily of structurally similar but functionally diverse proteins. J Biol Chem 276: 33293-33296, 2001

2. Gettins PG: Serpin structure, mechanism, and function. Chem Rev 102: 4751-4804, 2002.

3. Silverman GA, Whisstock JC, Askew DJ, et al: Human clade B serpins (ov-serpins) belong to a cohort of evolutionary dispersed intracellular proteinase inhibitor clades that protect cells from promiscuous proteolysis. Cell Mol Life Sci 61: 301-325, 2004.

4. Kato $\mathrm{H}$ and Torigoe $\mathrm{T}$ : Radioimmunoassay for tumor antigen of human cervical squamous cell carcinoma. Cancer 40: 1621-1628, 1977.

5. Izahara K, Ohta S, Kanaji S, Shiraishi H and Arima K: Recent progress in understanding the diversity of the human ov-serpin/ clade B serpin family. Cell Mol Life Sci 65: 2541-2553, 2008.

6. Takeshima N, Suminami Y and Takeda O: Expression of mRNA of SCC antigen in squamous cells. Tumour Biol 13: 338-342, 1992 .

7. Cataltepe S, Gornstein ER and Schick C: Co-expression of the squamous cell carcinoma antigens 1 and 2 in normal adult human tissues and squamous cell carcinomas. J Histochem Cytochem 48: 113-122, 2000.

8. Pontisso P, Calabrese F, Benvegnù L, et al: Overexpression of squamous cell carcinoma antigen variants in hepatocellular carcinoma. Br J Cancer 90: 833-837, 2004.

9. Giannelli G, Marinosci F, Sgarra C, Lupo L, Dentico P and Antonaci S: Clinical role of tissue and serum levels of SCCA antigen in hepatocellular carcinoma. Int J Cancer 116: 579-583, 2005 .

10. Suminami Y, Nagashima S and Vujanovic NL: Inhibition of apoptosis in human tumour cells by the tumour-associated serpin, SCC antigen-1. Br J Cancer 82: 981-989, 2000.

11. Katagiri C, Nakamishi J, Kadoya K and Hibino T: Serpin squamous cell carcinoma antigen inhibits UV-induced apoptosis via suppression of c-JUN NH2 terminal kinase. J Cell Biol 172: 983-990, 2006

12. Suminami Y, Nagashima S, Murakami A, et al: Suppression of a squamous cell carcinoma (SCC)-related serpin, SCC antigen, inhibits tumor growth with increased intratumor infiltration of natural killer cells. Cancer Res 61: 1776-1780, 2001.

13. Quarta S, Vidalino L, Ruvoletto MG, et al: SCCA over-expression induces cell proliferation and down-regulation of the adhesion system. J Clin Virol 36: S193, 2006.

14. Fausto N, Campbell JS and Riehle KJ: Liver regeneration. Hepatology 43: S45-S53, 2006.

15. Michalopoulos GK and DeFrances MC: Liver regeneration. Science 276: 60-66, 1997.
16. Fausto $\mathrm{N}$ and Webber EM: Liver regeneration. In: Liver: Biology and Pathobiology. Arias IM et al (eds) Raven Press, New York, pp1059-1084, 1994.

17. Michalopoulos GK: Liver regeneration. J Cell Physiol 213: 286-300, 2007.

18. Sakamoto T, Liu Z, Murase N, Ezure T, Yokomuro S, Poli V and Demetris AJ: Mitosis and apoptosis in the liver of interleukin-6deficient mice after partial hepatectomy. Hepatology 29: 403-411, 1999.

19. Jin X, Zimmers TA, Perez EA, Pierce RH, Zhang Z and Koniaris LG: Paradoxical effects of short- and long-term interleukin-6 exposure on liver injury and repair. Hepatology 43: 474-484, 2006.

20. Greene AK and Puder M: Partial hepatectomy in the mouse: technique and perioperative management. J Invest Surg 16: 99-102, 2003.

21. Bucher N: Regeneration of mammalian liver. Int Rev Cytol 15: 245-300, 1963.

22. De Falco S, Ruvoletto MG, Verdoliva A, et al: Cloning and expression of a novel hepatitis $\mathrm{B}$ virus-binding protein from HepG2 cells. J Biol Chem 39: 36613-36623, 2001.

23. Plumet S and Gerlier D: Optimized SYBR green real-time PCR assay to quantify the absolute copy number of measles virus RNAs using gene specific primers. J Vir Meth 128: 79-87, 2005.

24. Askew DJ, Askew YS, Kato Y, Turner RF, Dewar K, Lehoczky J and Silverman GA: Comparative genomic analysis of the clade B serpin cluster at chromosome 18q21: amplification with the mouse squamous cell carcinoma antigen locus. Genomics 85: 176-184, 2004.

25. Sakata Y, Arima K, Takeshita K, et al: Characterization of novel squamous cell carcinoma antigen-related molecules in mice. Biochem Biophys Res Commun 24: 1340-1345, 2004.

26. Guido M, Roskams T, Pontisso P, et al: Squamous cell carcinoma antigen in human liver carcinogenesis. J Clin Pathol 61: 445-447, 2008

27. Beneduce L, Castaldi F, Marino M, et al: Squamous cell carcinoma antigen-IgM complexes as novel biomarkers for hepatocellular carcinoma. Cancer 130: 2558-2565, 2005.

28. Peters M, Blinn G, Jostock T, Schirmacher P, Meyer zum Büschenfelde KH, Galle PR and Rose-John S: Combined interleukin 6 and soluble interleukin 6 receptor accelerates murine liver regeneration. Gastroenterology 119: 1663-1671, 2000

29. Naugler WE, Sakurai T, Kim S, Maeda S, Kim K, Elsharkawy AM and Karin M: Gender disparity in liver cancer due to sex differences in MyD88-dependent IL-6 production. Science 317: 121-124, 2007. 